\title{
Chromium (III) Oxide Nanostructures Synthesized from Vernonia Amygdalina Leaves Extract
}

\author{
Asratemedhin B. Habtemariam ${ }^{1, *(D)}$, Ashenafi K. Kereta ${ }^{1}$ \\ 1 Physics Department, College of Natural and Computational Sciences, Debre Berhan University, P. O. Box 445, Ethiopia \\ * Correspondence: asratemedhinbekele@dbu.edu.et;
}

Received: 25.08.2020; Revised: 25.09.2020; Accepted: 28.09.2020; Published: 2.10.2020

\begin{abstract}
This contribution reports first time synthesis of $\mathrm{Cr}_{2} \mathrm{O}_{3}$ nanostructures from chromium (III) chloride hexahydrate precursor using Vernonia amygdalina leaves extract as a reducing and stabilizing agent. Powder X-ray diffraction, Fourier-transform infrared spectroscopy, and scanning electron microscopy techniques were used to study the structural and morphological properties of the assynthesized $\mathrm{Cr}_{2} \mathrm{O}_{3}$ nanostructures. Powder X-ray diffraction patterns spectral analysis showed that hexagonal $\mathrm{Cr}_{2} \mathrm{O}_{3}$ nanostructures with an average crystallite size of $23.4 \mathrm{~nm}$ were synthesized with the minor appearance of $\mathrm{CrO}_{2}$. SEM images showed that the synthesized nanomaterials are granules. Fourier-transform infrared spectra represent a sharp absorption band at $552 \mathrm{~cm}^{-1}$, which indicates Cr-OCr vibrational and stretching modes.
\end{abstract}

Keywords: Bio-mediated; $\mathrm{Cr}_{2} \mathrm{O}_{3}$ nanostructures; granules; Vernonia amygdalina.

(C) 2020 by the authors. This article is an open-access article distributed under the terms and conditions of the Creative Commons Attribution (CC BY) license (https://creativecommons.org/licenses/by/4.0/).

\section{Introduction}

Chromium (III) oxide $\left(\mathrm{Cr}_{2} \mathrm{O}_{3}\right)$, among the various oxides of chromium, is the most stable oxide found in a wide range of temperature and pressure [1,2]. $\mathrm{Cr}_{2} \mathrm{O}_{3}$ is technologically important due to its numerous applications, including green pigment, catalysts, coating materials for UV protection, and visible light transmittance [3,4]. $\mathrm{Cr}_{2} \mathrm{O}_{3}$ is the hardest oxide that also exhibits many attractive functionalities among these lower coefficient of friction, high wear, and corrosion resistance, and good optical and adiabatic characteristics are key properties $[5,6]$. It also exhibits a high melting point $\left(2435^{\circ} \mathrm{C}\right)$ and high-temperature oxidation resistance [7-9]. Despite its intrinsic insulator nature, $\mathrm{Cr}_{2} \mathrm{O}_{3}$ films can exhibit either p-type or n-type semiconductor behavior, depending on the synthesis conditions [1]. The confluence of all these properties in $\mathrm{Cr}_{2} \mathrm{O}_{3}$ makes it a preferable material for the development of a broad range of industrial applications.

Chromium (III) oxides can be synthesized by different methods such as thermal decomposition [9-11] precipitation [12], chemical vapour deposition [2], sol-gel [8], hydrothermal $[13,14]$, solution combustion [15,16] and biological [1,17]. Among these, the biological (bio-mediated) method is non-toxic, inexpensive, and environmental friendly, which involves the use of bacteria, fungi, or plant materials to synthesize chromium (III) oxide, playing a significant role in controlling surface morphology and size of the material $[18,19]$.

So far, fewer studies have been reported on the synthesis of $\mathrm{Cr}_{2} \mathrm{O}_{3}$ nanostructures using different plant extracts. For instance, nano-sized $\mathrm{Cr}_{2} \mathrm{O}_{3}$ nanoparticles were synthesized from potassium dichromate solution reduction using Tridax procumbens leaf extract, which acts as 
a reducing agent [17]. Single-phase $\alpha-\mathrm{Cr}_{2} \mathrm{O}_{3}$ nanoparticles' were also synthesized using the red flower of Callistemon viminalis' extract [1]. In the present study, $\mathrm{Cr}_{2} \mathrm{O}_{3}$ nanostructures were successfully synthesized using Vernonia amygdalina (V. amygdalina) plant leaves extract as a reducing and stabilizing agent.

$V$. amygdalina is a small evergreen tree (about five-meter tall), a very popular plant that grows, preferably in most parts of tropical Africa [20-22]. The plant is commonly called bitter leaf due to its bitter taste [21] and known as 'Grawa' in Amharic (Ethiopia). V. amygdalina is known for its high production, as its seeds propagate easily by wind, high adaptability, and its ability to improve the soil fertility and growth of crops [23]. In developing countries, disease treatment using herbal plants plays a key role in medication. In the rural highlands of Ethiopia, the water extract of $V$. amygdalina leaves serves as a traditional medicine for the prevention of stomach-ache as it is a non-toxic plant. Phytochemical analysis of $V$. amygdalina revealed high levels of flavonoids, phenol, saponin, tannins, and alkaloids [24]. It exhibits excellent antioxidant properties due to the presence of flavonoid and phenolic constituents [22,24], and this has been reported in an attempt to synthesize NiO nanoparticles [25].

\section{Materials and Methods}

\subsection{Materials.}

Chromium (III) chloride $\left(\mathrm{Cr}_{2} \mathrm{Cl}_{3} \bullet 6 \mathrm{H}_{2} \mathrm{O}\right)$ and distilled water were purchased from Sigma-Aldrich. Fresh and healthy leaves of $V$. amygdalina were collected from Hawariat town, Gurage zone in the South region, Ethiopia.

\subsection{Synthesis of $\mathrm{Cr}_{2} \mathrm{O}_{3}$ nanoparticles.}

Freshly collected and taxonomically authenticated leaves of $V$. amygdalina were washed thoroughly with tap water followed by distilled water to avoid dust and impurities and shade dried for a couple of weeks. The dried $V$. amygdalina leaves were powdered and stored in an airtight plastic bag for subsequent use.
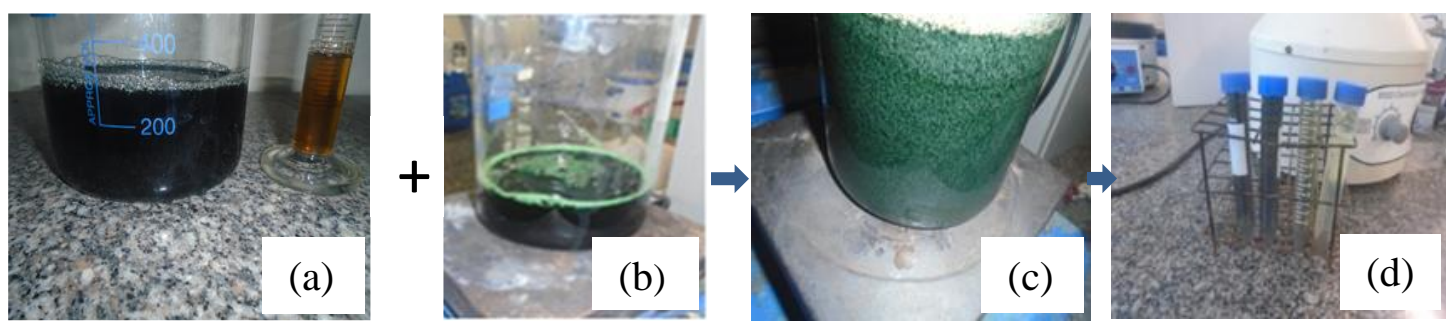

Figure 1. Schematic synthesis process of $\mathrm{Cr}_{2} \mathrm{O}_{3}$ nanostructures.

To prepare the extract solution, a weighed $10 \mathrm{gm}$ of the dried leaves were added into $100 \mathrm{ml}$ of distilled water in a flask and boiled at $60^{\circ} \mathrm{C}$ for $30 \mathrm{~min}$. Then the extract was cooled to room temperature and filtered (Whatman No. 1) to get the brown color aqueous extract solution shown in Figure 1a, and a $0.1 \mathrm{M}$ solution of the precursor was prepared using $\mathrm{CrCl}_{3} \cdot 6 \mathrm{H}_{2} \mathrm{O}$ as shown in Figure $1 \mathrm{~b}$.

The synthesis protocol employed was the commonly applied process [25]. In a typical experiment, $50 \mathrm{ml}$ of the prepared precursor solution was mixed with $40 \mathrm{ml}$ of $V$. amygdalina leaves extract solution in a beaker dropwise. After $30 \mathrm{~min}$. The solution changes color from dark to green, indicating the formation of chromium oxide nanostructures (Figure 1c). The purpose of the plant extract here is to reduce and stabilize the synthesized nanostructures 
[26,27]. The solution was heated at $60{ }^{\circ} \mathrm{C}$ for $30 \mathrm{~min}$. under continuous magnetic stirring. After cooling down to room temperature, the resulting solution was centrifuged at $3500 \mathrm{rpm}$ and washed repeatedly using distilled water to avoid impurities. As it is assumed that $\mathrm{Cr}_{2} \mathrm{O}_{3}$ nanostructures can be obtained in the range of $110-217^{\circ} \mathrm{C}[10]$, the final precipitate was ovendried at a temperature of $120{ }^{\circ} \mathrm{C}$. The dried powder was annealed at $500{ }^{\circ} \mathrm{C}$ in an air furnace for $2 \mathrm{hrs}[1,15]$ to get $\mathrm{Cr}_{2} \mathrm{O}_{3}$ nanostructures.

\section{Results and Discussion}

\subsection{X-ray diffraction (XRD) analysis.}

For phase identification, X-ray diffraction (XRD) patterns were recorded from an Xray diffractometer with 2 theta geometry, operating with $\mathrm{CuK} \alpha$ radiation $(\lambda=1.540598 \dot{\mathrm{A}})$ at a voltage of $40 \mathrm{kV}$ and current of $30 \mathrm{~mA}$. The XRD patterns of the powder sample were recorded with a step size of 0.02 at a scan speed of $3 \% \mathrm{~min}$ and a counting time of $0.4 \mathrm{sec}$. $/ \mathrm{step}$ in the $10^{\circ}$ to $80^{\circ} 2 \Theta$ range. The resulting XRD patterns of the as-prepared nanopowder can be indexed to the hexagonal structure of $\mathrm{Cr}_{2} \mathrm{O}_{3}$ from JCPDS card no. 96-210-4123 (Figure 2a), and the patterns are compared to the standard using match software Figure ( $2 b)$. The peaks are indexed to $24.37^{\circ}, 33.56^{\circ}, 36.28^{\circ}, 41.53^{\circ}, 50.23^{\circ}, 55.5^{\circ}, 63.47^{\circ}$, and $65.47^{\circ}$, which corresponds to the crystal planes (102), (104), (110), (113), (204), (116), (214) and (300), respectively, of crystalline $\mathrm{Cr}_{2} \mathrm{O}_{3}$.

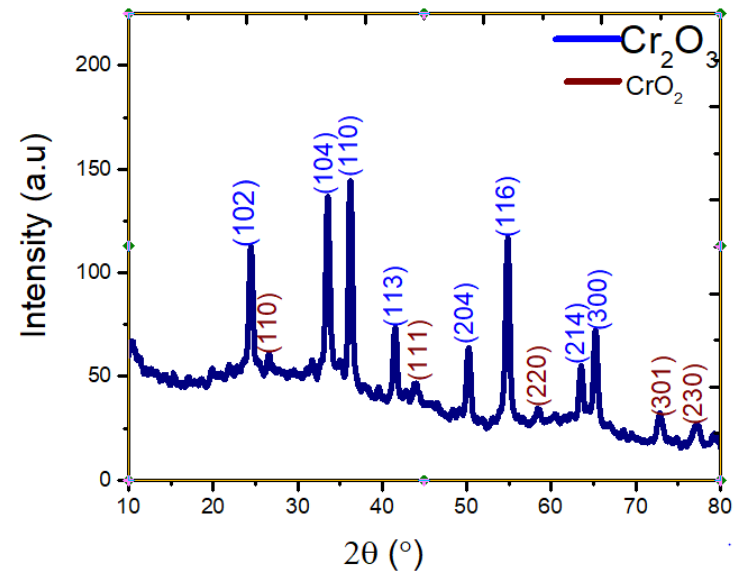

(a)

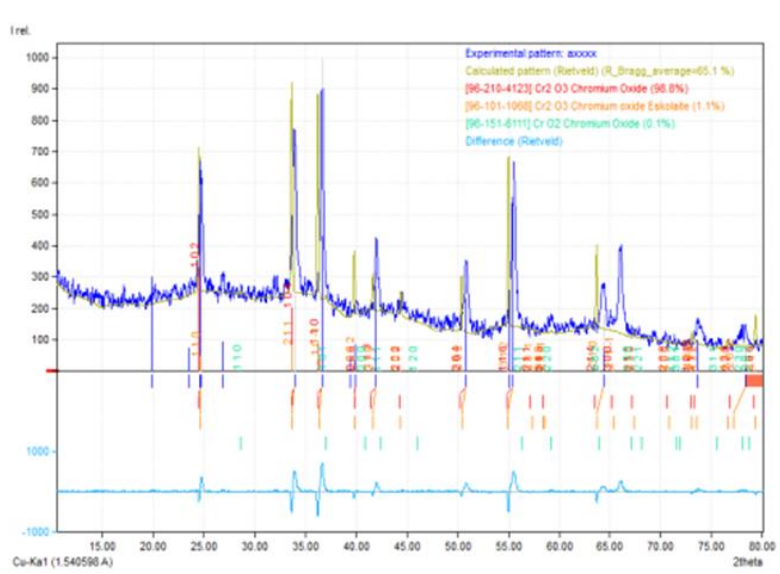

(b)

Figure 2. XRD patterns of $\mathrm{Cr}_{2} \mathrm{O}_{3}$ nanostructures(a) and Retvield refined XRD data (b).

Inter planar spacing ' $d$ ' for hexagonal phase structure of $\mathrm{Cr}_{2} \mathrm{O}_{3}$, is determined by the following relation:

$$
\frac{1}{d^{2}}=\frac{4\left(h^{2}+h k+k^{2}\right)}{3 a^{2}}+\frac{l^{2}}{c^{2}}
$$

where ' $h$ ', ' $k$ ', and 'l' are miller indices.

Average crystallite size $D_{h k l}$ was estimated using the Scherrer equation from prominent XRD peaks:

$$
D_{h k l}=\frac{k \lambda}{d \cos \theta}
$$

where ' $k$ ' is a shape factor ( $\mathrm{k}=0.9)$, ' $\lambda$ ' is the X-ray wavelength, and ' $\beta$ ' and ' $\theta$ ' are the halfwidth of the peak and half of the Bragg angle, respectively. Using this equation, the crystallite sizes of $\mathrm{Cr}_{2} \mathrm{O}_{3}$ nanostructures was calculated to be $23.4 \mathrm{~nm}$. 


\subsection{Fourier-transform infrared (FTIR) spectroscopy.}

Spectral analysis was recorded using a Fourier-transform infrared instrument whose spectral range is from $4000 \mathrm{~cm}^{-1}$ to $400 \mathrm{~cm}^{-1}$. Figure $3 \mathrm{a}$ is representative FTIR spectra peak of $V$. amygdalina leaves extract indexed to $3354 \mathrm{~cm}^{-1}, 2927 \mathrm{~cm}^{-1}, 2857 \mathrm{~cm}^{-1}, 1647 \mathrm{~cm}^{-1}, 1402 \mathrm{~cm}^{-}$ $1,1251 \mathrm{~cm}^{-1}, 1059 \mathrm{~cm}^{-1}$ and $611 \mathrm{~cm}^{-1}$. The broad absorption band around $3354 \mathrm{~cm}^{-1}$ is related to the $\mathrm{O}-\mathrm{H}$ bond stretching of the phenolic group, the peaks at $2927 \mathrm{~cm}^{-1}$ and $2857 \mathrm{~cm}^{-1}$ are related to the $\mathrm{C}-\mathrm{H}$ bending, and the peaks at $1647 \mathrm{~cm}^{-1}, 1402 \mathrm{~cm}^{-1}$, and $1251 \mathrm{~cm}^{-1}$ are related to the $\mathrm{N}-\mathrm{H}$ bending [28]. The absorption spectra of $\mathrm{Cr}_{2} \mathrm{O}_{3}$ nanostructures are observed at 3396 $\mathrm{cm}^{-1}, 2920 \mathrm{~cm}^{-1}, 2853 \mathrm{~cm}^{-1}, 1605 \mathrm{~cm}^{-1}, 1402 \mathrm{~cm}^{-1}, 1039 \mathrm{~cm}^{-1}$, and $552 \mathrm{~cm}^{-1}$, as shown in Figure $3 \mathrm{~b}$. The broadband observed at $3396 \mathrm{~cm}^{-1}$ is due to the $-\mathrm{OH}$ stretching modes and the peaks at $1605 \mathrm{~cm}^{-1}$ and $1039 \mathrm{~cm}^{-1}$ indicate the presence of hydroxyl groups associated with $\mathrm{Cr}^{3+}$ ions [10]. The peak at $2920 \mathrm{~cm}^{-1}$ can be assigned to the $\mathrm{C}-\mathrm{H}$ stretching and bending vibrations [11]. Metal oxides, generally, exhibit absorption bands around $1000 \mathrm{~cm}^{-1}$ as a result of inter-atomic vibrations. Hence, the weak band around $1039 \mathrm{~cm}^{-1}$ is due to $\mathrm{Cr}=\mathrm{O}$ vibration modes, and the band at $552 \mathrm{~cm}^{-1}$ is the characteristic stretching bonds of $\mathrm{Cr}-\mathrm{O}-\mathrm{Cr}$, which indicate the presence of hexagonal $\mathrm{Cr}_{2} \mathrm{O}_{3}$ nanostructure [10].

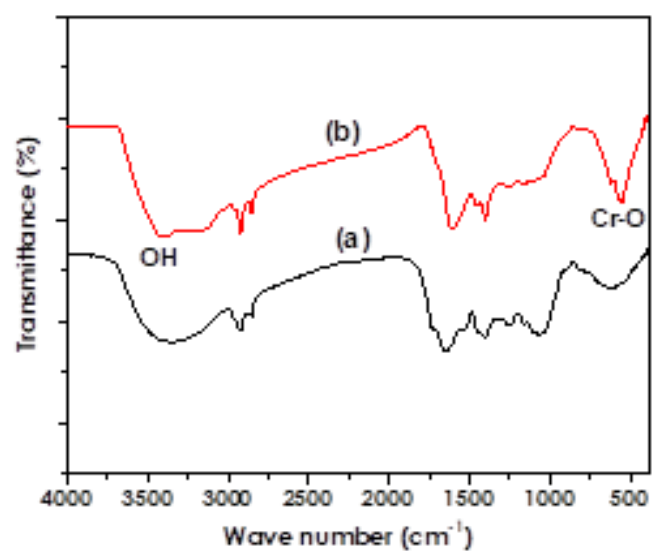

Figure 3. FTIR spectra of (a) V. amygdalina leaf extract and (b) synthesized $\mathrm{Cr}_{2} \mathrm{O}_{3}$ nanostructures.

\subsection{Scanning electron microscopy (SEM).}

The morphological studies of $\mathrm{Cr}_{2} \mathrm{O}_{3}$ nanostructures synthesized using $V$. amygdalina leave extracts were analyzed by scanning electron microscopy, SEM model JSM-IT300LV, in the micrometer scale. SEM images of the samples are shown in Figure 4 below. The images of the as-synthesized nanostructures revealed that it is granular in structure.

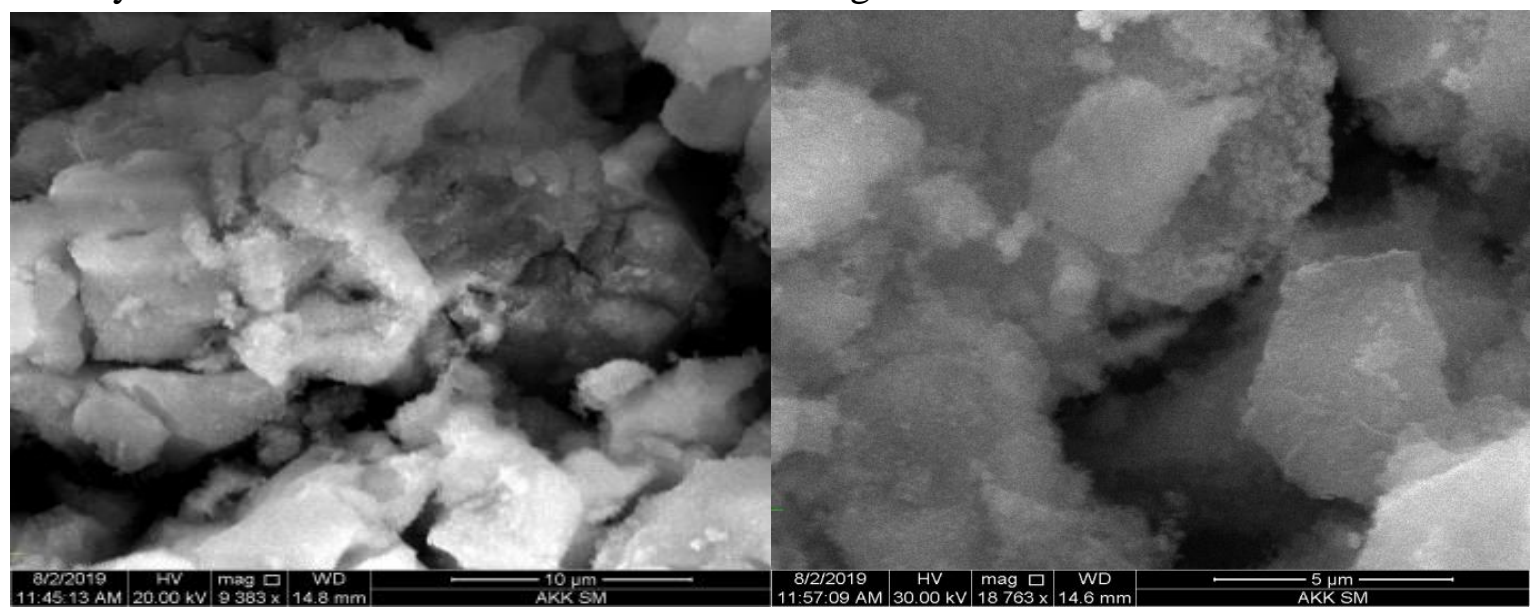

Figure 4. SEM images of $\mathrm{Cr}_{2} \mathrm{O}_{3}$ nanostructures synthesized from $V$. amygdalina leaf extracts. 


\section{Conclusions}

In summary, a simple, cost-effective, and eco-friendly biological technique was employed for the successful synthesis of $\mathrm{Cr}_{2} \mathrm{O}_{3}$ nanostructures using $\mathrm{CrCl}_{3} \cdot 6 \mathrm{H}_{2} \mathrm{O}$ as a precursor, and aqueous extract of $V$. amygdalina leaves as a reducing and stabilizing agent under low-temperature condition. The mean crystallite size was $23.4 \mathrm{~nm}$, as confirmed from the detailed analysis of XRD patterns using the Scherrer equation. Rietveld refinement of XRD spectra also confirmed that $\mathrm{Cr}_{2} \mathrm{O}_{3}$ was dominantly observed in the pattern with minor existence of $\mathrm{CrO}_{2}$ peaks as an impurity. V. amygdalina leaf extract is, therefore, a good reducing and stabilizing agent for the synthesis of $\mathrm{Cr}_{2} \mathrm{O}_{3}$ nanostructures. The as-synthesized $\mathrm{Cr}_{2} \mathrm{O}_{3}$ nanostructures were also stable, and this shows that the synthesis method is reproducible for large scale production.

\section{Funding}

This research received no external funding.

\section{Acknowledgments}

The researchers would like to express their heartfelt gratitude to the Materials Science and Engineering Department at Addis Ababa Science and Technology University for running SEM characterization and Chemistry Department at Addis Ababa University for FTIR characterization. The researchers are also thankful to the Materials Science and Engineering Department at Adama Science and Technology University for running XRD characterization.

\section{Conflicts of Interest}

The authors declare no conflict of interest.

\section{References}

1. Sone, B.; Manikandan, E.; Gurib-Fakim, A.; Maaza, M. Single-phase $\alpha$-Cr2O3 nanoparticles' green synthesis using Callistemon viminalis' red flower extract. Green Chemistry Letters and Reviews 2016, 9, 85-90, https://doi.org/10.1080/17518253.2016.1151083.

2. Sousa, P.; Silvestre, A.J.; Conde, O. Cr2O3 thin films grown at room temperature by low pressure laser chemical vapour deposition. Thin Solid Films 2011, 519, 3653-3657, https://doi.org/10.1016/j.tsf.2011.01.382.

3. Shu-ting Liang, H.-1.Z., Min-ting Luo, Ke-jun Luo, Ping Li, Hong-bin Xu, Yi Zhang. Colour performance investigation of a $\mathrm{Cr} 2 \mathrm{O} 3$ green pigment prepared via the thermal decomposition of CrOOH. Ceram. Int. 2014, 40, 4367-4373, https://doi.org/10.1016/j.ceramint.2013.08.107.

4. Sangeetha, S.; Basha, R.; Sreeram, K.J.; Sangilimuthu, S.N.; Nair, B.U. Functional pigments from chromium (III) oxide nanoparticles. Dyes Pigm 2012, 94, 548-552, https://doi.org/10.1016/j.dyepig.2012.03.019.

5. Pang, X.; Gao, K.; Volinsky, A.A. Microstructure and mechanical properties of chromium oxide coatings. $J$. Mater. Res. 2007, 22, 3531-3537, https://doi.org/10.1557/JMR.207.0445.

6. Zhang, Y.; Li, J.; Huang, J.; Ding, C. Mechanical and tribological properties of plasma-sprayed Cr $3 \mathrm{C} 2-\mathrm{NiCr}$, WC-Co, and $\mathrm{Cr} 2 \mathrm{O} 3$ coatings. J. Therm. Spray Technol. 1998, 7, 242-246, https://doi.org/10.1361/105996398770350981.

7. Celik, E.; Tekmen, C.; Ozdemir, I.; Cetinel, H.; Karakas, Y.; Okumus, S. Effects on performance of Cr2O3 layers produced on Mo/cast-iron materials. Surf. Coat. Technol. 2003, 174, 1074-1081.

8. El-Sheikh, S.; Mohamed, R.; Fouad, O. Synthesis and structure screening of nanostructured chromium oxide powders. J Alloy Compd 2009, 482, 302-307, https://doi.org/10.1016/j.jallcom.2009.04.011.

9. Gibot, P.; Vidal, L. Original synthesis of chromium (III) oxide nanoparticles. J Eur Ceram Soc 2010, 30, 911915, https://doi.org/10.1016/j.jeurceramsoc.2009.09.019.

10. Li, L.; Yan, Z.F.; Lu, G.Q.; Zhu, Z.H. Synthesis and structure characterization of chromium oxide prepared by solid thermal decomposition reaction. $J$ Phys Chem $B$ 2006, 110, 178-183, https://doi.org/10.1021/jp053810b. 
11. Li, L.; Zhu, Z.; Yao, X.; Lu, G.; Yan, Z. Synthesis and characterization of chromium oxide nanocrystals via solid thermal decomposition at low temperature. Microporous Mesoporous Mater. 2008, 112, 621-626, https://doi.org/10.1016/j.micromeso.2007.10.044.

12. Zhao, W.; Zhang, H.; Liu, J.; Deng, X.; Bi, Y.; Zhang, S. Preparation of Cr2O3 nanoparticles via surfactantsmodified precipitation method and their catalytic effect on nitridation of silicon powders. J Ceram Soc Jpn 2017, 125, 623-627, https://doi.org/10.2109/jcersj2.17047.

13. Pei, Z., Zhang, Yi. A novel method to prepare Cr2O3 nanoparticles. Mater. Lett. 2008, 62, 504-506, https://doi.org/10.1016/j.matlet.2007.05.073.

14. Pei, Z.; Xu, H.; Zhang, Y. Preparation of $\mathrm{Cr} 2 \mathrm{O} 3$ nanoparticles via $\mathrm{C} 2 \mathrm{H} 5 \mathrm{OH}$ hydrothermal reduction. J Alloy Compd 2009, 468, L5-L8, https://doi.org/10.1016/j.jallcom.2007.12.086.

15. Fu, X.-Z.L., Xiao-Xiong Luo, Jing-Li Chuang, Karl T. Sanger, Alan R. Krzywicki, Andrzej. Ethane dehydrogenation over nano-Cr2O3 anode catalyst in proton ceramic fuel cell reactors to co-produce ethylene and electricity. J. Power Sources 2011, 196, 1036-1041, https://doi.org/10.1016/j.jpowsour.2010.08.043.

16. Lima, M.; Bonadimann, R.; de Andrade, M.; Toniolo, J.; Bergmann, C. Nanocrystalline Cr2O3 and amorphous CrO3 produced by solution combustion synthesis. J Eur Ceram Soc 2006, 26, 1213-1220, https://doi.org/j.jeurceramsoc.2005.01.042.

17. Ramesh, C.; Mohan Kumar, K.; Latha, N.; Ragunathan, V. Green synthesis of Cr2O3 nanoparticles using Tridax procumbens leaf extract and its antibacterial activity on Escherichia coli. Curr Nanoscience 2012, 8, 603-607, https://doi.org/10.2174/157341312801784366.

18. Habtemariam, A.B.; Sibhatu, A.K.; Weldegebrieal, G.K.; Zelekew, O.A.; Tekletsadik, B.T. Bio-mediated synthesis of $\mathrm{ZnO}$ nanostructures from Thymus Schimperi leaves extract and its antibacterial and photocatalytic activities. Lett Appl NanoBioSci 2020, 9, 808-813.

19. Mittal, A.K.; Chisti, Y.; Banerjee, U.C. Synthesis of metallic nanoparticles using plant extracts. Biotechnol. Adv. 2013, 31, 346-356, https://doi.org/10.1016/j.biotechadv.2013.01.003.

20. Abosi, A.O.; Raseroka, B.H. In vivo antimalarial activity of Vernonia amygdalina. Br J Biomed Sci 2003, 60, 89-91, https://doi.org/ 10.1080/09674845.2003.11783680.

21. Farombi, E.O.; Owoeye, O. Antioxidative and chemopreventive properties of Vernonia amygdalina and Garcinia biflavonoid. Int $J$ Environ Res Publ Health 2011, 8, 2533-2555, https://doi.org/10.3390/ijerph8062533.

22. Erasto, P.; Grierson, D.; Afolayan, A. Antioxidant constituents in Vernonia amygdalina Leaves. Pharm Biol 2007, 45, 195-199, https://doi.org/10.1080/13880200701213070 .

23. Mekoya, A.; Oosting, S.J.; Fernandez-Rivera, S.; Van der Zijpp, A. Multipurpose fodder trees in the Ethiopian highlands: Farmers' preference and relationship of indigenous knowledge of feed value with laboratory indicators. Agricultural Systems 2008, 96, 184-194, https://doi.org/10.1016/j.agsy.2007.08.001.

24. Atangwho, I.; Ebong, P.; Eyong, E.; Williams, I.; Eten, M.; Egbung, G. Comparative chemical composition of leaves of some antidiabetic medicinal plants: Azadirachta indica, Vernonia amygdalina and Gongronema latifolium. African Journal of Biotechnology 2009, 8.

25. Habtemariam, A.B.; Oumer, M. Plant Extract Mediated Synthesis of Nickel Oxide Nanoparticles. Mater Int 2020, 2, 205-209, https://doi.org/10.33263/Materials22.205209.

26. Ahmed Mohamed, H.E.; Afridi, S.; Khalil, A.T.; Zohra, T.; Ali, M.; Alam, M.M.; Ikram, A.; Shinwari, Z.K.; Maaza, M. Phyto-fabricated $\mathrm{Cr} 2 \mathrm{O} 3$ nanoparticle for multifunctional biomedical applications. Nanomedicine 2020, 15, 1653-1669, https://doi.org/10.2217/nnm-2020-0129.

27. Iqbal, J.; Abbasi, B.A.; Munir, A.; Uddin, S.; Kanwal, S.; Mahmood, T. Facile green synthesis approach for the production of chromium oxide nanoparticles and their different in vitro biological activities. Microscopy Research and Technique 2020, 83, 706-719, https://doi.org/10.1002/jemt.23460.

28. Aisida, S.O.; Madubuonu, N.; Alnasir, M.H.; Ahmad, I.; Botha, S.; Maaza, M.; Ezema, F.I. Biogenic synthesis of iron oxide nanorods using Moringa oleifera leaf extract for antibacterial applications. Applied Nanoscience 2020, 10, 305-315, https://doi.org/10.1007/s13204-019-01099-x. 